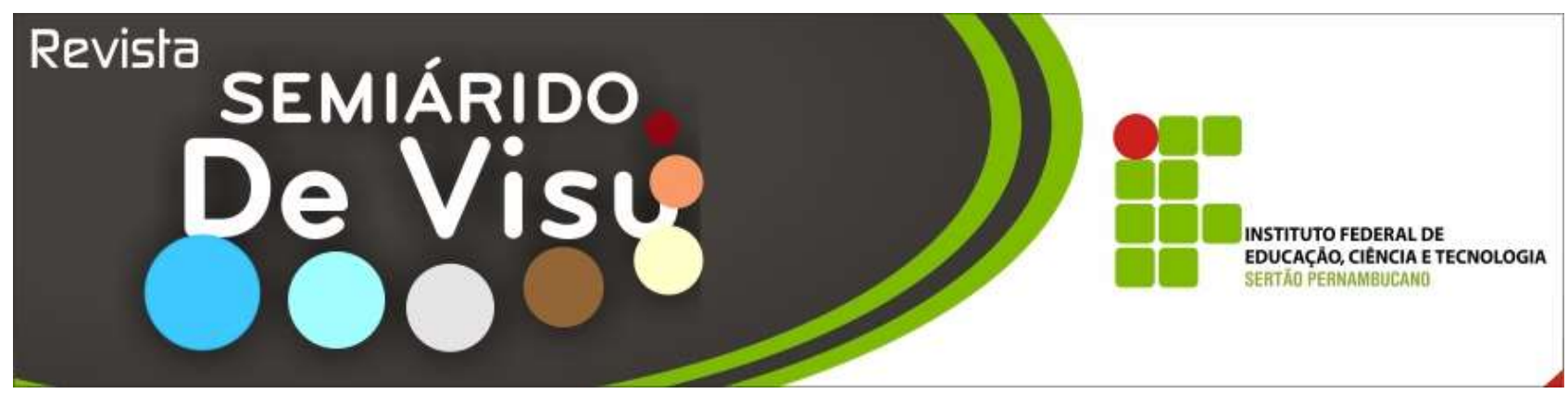

\title{
Formação profissional em Recursos Educacionais Abertos
}

\author{
Francisco Kelsen de Oliveira ${ }^{1}, K_{\text {Kélvya Freitas Abreu², Antônio Anderson da Silva Gomes }}^{3}$ \\ 1,2,3 Instituto Federal de Educação, Ciência e Tecnologia do Sertão Pernambucano - campus Salgueiro. BR 232, Km 508, sentido \\ Recife, Zona Rural - Salgueiro - PE - Brasil. CEP: 56.000-000 / Telefone: (87) 3421.0050 / E-mail: ${ }^{1}$ francisco.oliveira@ifsertao- \\ pe.edu.br; ${ }^{2}$ kelvya.freitas@ifsertao-pe.edu.br; ${ }^{3}$ antonioandersom@outlook.com
}

\begin{abstract}
RESUMO: Este artigo objetiva traçar um perfil dos docentes participantes do Curso de Recursos Educacionais Abertos (CREA) e levantar os requisitos de ambientes e ferramentas que promovam uso e adoção dos Recursos Educacionais Abertos (REA). Para isso, o CREA abordou conceitos, definições, tecnologias e licenças de REAs; modelos de negócios, repositórios e ambientes de compartilhamento de exemplos de REAs, e práticas educacionais abertas (PEA). Nessa ocasião, aspectos qualitativos e quantitativos foram considerados e analisados a partir dos instrumentos de coleta de dados como questionários online, bem como foram observadas as interações nas discussões dos participantes na Rede Social Educacional (RSE) Edmodo. O uso das ferramentas online para oferta do CREA favoreceu a participação de professores dos estados do Ceará e Pernambuco. A análise dos resultados do CREA, então, tornou possível perceber o interesse dos participantes do CREA em usar ou adequar REAs e PEAs em seus ambientes laborais, já que alguns partícipes conheciam os conceitos, mas não trabalharam com REAs e PEAs, enquanto outros desconheciam tais possibilidades.
\end{abstract}

Palavras-chave: REA, formação docente, tecnologia de informação e comunicação.

\section{Training on Open Educational Resources}

\begin{abstract}
This article aims to draw a profile of the participants in the course of open educational resources (CREA) and raise the requirements of environments and tools that promote the use and adoption of open educational resources (OER). For this, the CREA approached concepts, definitions, technology and license of OERs; business models, repositories and sharing environments of OERs examples and open educational practices (OEP). On that occasion, the qualitative and quantitative aspects were considered and analyzed from the data collection instruments like questionnaires online, as well as the interactions were observed in the discussions of the participants in Social Network Educational (SNE) Edmodo. The use of online tools to offer the CREA favored the participation of teachers from the States of Ceará and Pernambuco. The analysis of the results of CREA, then, made it possible to understand the interest of the participants in the CREA in use or adapt OERs and OEPs in their working environments, since some participants knew the concepts, but didn't work with OERs and OEPs, while others were unaware of such possibilities.
\end{abstract}

key words: OER, teacher training, information and communication technology. 
(OLIVEIRA; ABREU, GOMES, 2015)

\section{Introdução}

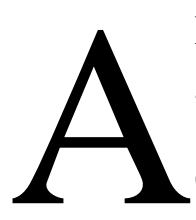

Educação é um direito fundamental garantido por nossa carta magna em seu art. $6^{\circ}$ (BRASIL, 1988). Diante deste direito, ao longo dos anos outras ações fomentadas por gestos de políticas educacionais, fez-se perceber mudanças sobretudo na expansão da oferta de vagas nas instituições de ensino brasileiras, seja no ensino superior ou na educação básica. Porém ainda há diversos problemas a serem solucionados, debatidos e analisados, especialmente, quando se trata dos baixos índices de rendimento dos alunos como visualizados em resultados de inúmeras avaliações de larga escala (OLIVEIRA, 2010). Cabe destacar que essas avaliações se destinam a identificar justamente pontos fortes e fracos para traçar medidas a fim de potencializar os aspectos positivos ou lançam estratégias para reduzir os negativos na área educacional.

Logo, alguns projetos e programas foram e são implantados para mitigar ou acabar com esses percalços, visando melhorar a qualidade do ensino, como por exemplo: a criação de escolas em tempo integral; a oferta da merenda escolar aos alunos; a distribuição dos livros didáticos aos discentes da Educação Básica através do Programa Nacional do Livro Didático (PNLD); a inclusão de computadores, tablets e internet nas escolas através dos Projetos Um Computador por Aluno (ProUCA) e Programa Nacional de Tecnologia Educacional (ProINFO); bem como o desenvolvimento de softwares educativos; entre outros. Contudo, os resultados obtidos ainda não condizem com os investimentos na área.

$\mathrm{O}$ número de projetos implantados, em especial, com uso das ferramentas de Tecnologia da Informação e Comunicação (TIC) em âmbito educacional não alcançam o sucesso esperado se aliado a possibilidade das TIC's colaborarem nas práticas educacionais, objetivando mudar o cenário diante de certames, como: Provinha Brasil, Sistema de Avaliação da Educação Básica (SAEB) e Programa Internacional de Avaliação de Estudantes (PISA). As poucas avaliações e projetos pilotos realizados em nosso país demonstram problemas relacionados à implementação e ao uso das tecnologias dentro da escola pública (CYSNEIROS, 2001; LAVINAS; CAVENAGHI, 2010; SORJ; LISSOVSKY, 2011).

Desta forma, Cornils (2011) enfatiza que o uso inadequado dos produtos, dos materiais ou das ferramentas comprometem as funções a serem desempenhadas, assim como os objetivos a serem alcançados, caso não haja uma formação/capacitação dos docentes. Vale salientar que além disso, existem outros entraves metodológicos na execução de um projeto de sucesso, pois ocorre, por muitas vezes, a cópia de projetos e programas existentes em outros países e quando trazidos para cá são implementados sem um estudo prévio de viabilidade em um ambiente diferente do que estava funcionando e dando certo. Mais especificamente, outra causa para o insucesso na implementação das TIC's no âmbito educacional está na impossibilidade de adequação à nossa realidade, já que muitos produtos e ferramentas são vendidos sob licença de uso que impedem qualquer tipo de modificação, principalmente, quando se trata de software.

Cuban (2001) ainda cita problemas de gestão e até mesmo de adequação (quando possível) de programas e projetos, pois não se levam em consideração os contextos e as culturas escolares que propiciam uma variedade de desafios. Caso os materiais contivessem a possibilidade de serem adequados ou mesmo customizados às realidades dos alunos, bem como os professores tivessem capacitação e tempo para alterá-los e compartilhá-los, independente de ser um livro, música, vídeo ou aplicativo, os conteúdos e materiais estariam mais próximos das realidades educacionais e sem ter barreiras legais que impedissem a difusão do conhecimento ao torná-lo uma propriedade privada cujo acesso é limitado e restrito a apenas um pequeno grupo com poder financeiro para adquirir.

Deste modo, enfatiza-se para este estudo que as TICs contribuíram para facilitar o acesso aos conteúdos produzidos por pessoas ao redor do mundo ao tornarem-se disponíveis na Internet a todos os interessados que possam 
colaborar para as possíveis melhorias. Além disso, auxiliaram e auxiliam em diversas atividades cotidianas, tendo em vista proporcionar maior convivência diante da rapidez das informações na sociedade de hoje (seja para simples facilidade de comunicação entre pessoas em locais geograficamente distantes, seja para proporcionar capacitação e aperfeiçoamento profissional ou mesmo para fins laborais, como gerenciamento de tarefas, edição de textos, planilhas, vídeos e imagens).

Logo, esse modelo ganha destaque quando funciona de modo satisfatório com os softwares livres (SL). Aplicações essas que são desenvolvidos por programadores que disponibilizam seus códigos no intuito de que outros possam usar, estudar, alterar e distribuir, conforme mencionam Taurion (2004) e Free Software Foundation (FSF, 2014). Montoya e Aguilar (2010) afirmam ainda que os Recursos Educacionais Abertos (REA) são baseados nos princípios dos SL, já que possuem as liberdades 4Rs: reusar, revisar, remixar e redistribuir.

A mesma ideia seria trabalhada, complementa Montoya, de igual forma com os recursos educacionais, pois poder-se-ia utilizar e melhorar diversos materiais desenvolvidos pelos professores que compartilhariam seus conteúdos contribuindo com a aprendizagem dos alunos, bem como ter-se-iam materiais atualizados e com adequações às diferentes realidades educacionais, coadunando com o conceito de Conteúdo Aberto apresentado por Wiley (2005).

Portanto, este projeto objetivou identificar as necessidades dos docentes para promover o uso de REA, proporcionar experiências com REAs e levantar requisitos das ferramentas e ambientes de compartilhamento de REAs. O Curso de Recursos Educacionais Abertos (CREA) aos docentes e demais interessados no assunto a fim de apresentar, difundir e compartilhar conceitos, definições, exemplos e repositórios de REAs, bem como socializar Práticas Educacionais Abertas (PEAs) entre os participantes, foi promovido pelos presentes pesquisadores.

Assim, vale sinalizar que, uma sondagem inicial foi realizada no início do
CREA para identificar o nível de conhecimento dos participantes com o intuito de adequar os conteúdos previstos às expectativas dos participantes com uma linguagem adequada ao nível dos partícipes, mediante a aceitação do Termo de Consentimento Livre e Esclarecido aplicado aos participantes para deixar claro a todos que os dados do curso seriam coletados e analisados pela pesquisa científica. A aplicação do termo apresentou ainda a finalidade de se ter a autorização no uso dos dados, bem como salvaguardar os direitos de cada participante, inclusive de sigilo total de suas identidades.

Assim sendo, o curso proporcionou interação entre participantes baseada nos materiais didáticos sobre REAs, tendo em vista oferecer a formação profissional e a troca de experiências, que poderão ser desenvolvidas ou adequadas nos seus respectivos contextos de ensino.

\section{Recursos Educacionais Abertos}

Os REA's, agregados à educação aberta, são capazes de enriquecer a aprendizagem dos alunos, pois essas e outras iniciativas facilitam a prática de educação, conforme a Declaração da Cidade do Cabo (2007). Logo, os REA's são materiais de ensino, aprendizado e pesquisa em variados tipos de suporte ou de mídia, sob domínio público ou licenciados de maneira aberta, permitindo que sejam utilizados ou adaptados por usuários. (UNESCO, 2011).

De acordo com Amiel, Orey e West (2011), a colocação da UNESCO ao dizer que esses recursos estão sob domínio público e de maneira aberta evidencia que os mesmos podam ser utilizados ou adaptados por terceiros, a fim de facilitar o acesso, de serem veiculados em diferentes tipos de mídias e formato, sendo o foco principal apoiar o acesso ao conhecimento.

Para a criação do REA, existem pelo menos três pontos de vista que cabem ser destacados: 1) produzir material para compartilhar com seus colegas; 2) usar materiais produzidos por colegas de forma a tornar o planejamento das aulas em uma tarefa verdadeiramente colaborativa; 3) a produção dos materiais já pode ser realizada, tendo em 
vista distribuí-los aos seus alunos, seja em forma impressa ou ainda disponibilizando em algum repositório online (MORAIS; RIBEIRO; AMIEL, 2014).

Alguns educadores que possuem experiências com REA's utilizam esses repositórios para a procura de materiais que possam ser incluídos nas suas técnicas pedagógicas denominadas de Práticas Educacionais Abertas (PEA) - se referem ao uso de REA em conjunto com métodos adequados. Segundo Conole et al. (2010), uma PEA é um conjunto de atividades relacionadas à criação, uso e reuso de REA. Assim, além de usar o material educacional para enriquecer a prática pedagógica, o docente consegue escolher ou adequar materiais que possibilitem a elaboração de esquemas de ação, a construção de novos conhecimentos e o estabelecimento de relações entre o que está sendo estudado e o contexto em que estão inseridos.

Após o processo de criação ou adaptação desses recursos e práticas de uso, necessita-se de um ambiente para o armazenamento e compartilhamento, que são os repositórios. Esses funcionam como depósitos virtuais, onde ficam armazenados, hospedados e organizados esses materiais com fins educacionais.

Portanto, a busca por um material é de fácil utilização, pois geralmente esses repositórios solicitam alguns dados para realizar uma busca, como o componente curricular, a área ou disciplina, tipo de recursos entre outros, etc. Esses metadados também são solicitados pelos autores no momento da inclusão do recurso no repositório, que auxiliará nas buscas futuras a partir desses aspectos relacionados aos materiais salvos no ambiente.

\section{Redes sociais e ensino}

Além das possibilidades de entretenimento e comunicação, as redes sociais possibilitam também o uso de novas estratégias e ferramentas para apoiar a aprendizagem, oferecendo práticas inovadoras ao processo de ensino e aprendizagem.
Segundo Silva e Cogo (2007, apud CARITÁ; PADOVAN; SANCHES, 2011, p. 3 ), essas tecnologias estão transformando as maneiras de ensinar e aprender, oferecendo maior versatilidade, interatividade e flexibilidade de tempo e de espaço no processo educacional. Para Caritá, Padovan e Sanches (2011), as redes sociais podem motivar as pessoas a buscarem conteúdos desejados e fazerem desses ambientes seus repositórios de objetos de aprendizagem, salas de discussões e de compartilhamentos de conhecimentos e de recursos. Porém, há que se levar as pessoas a refletirem seus esquemas mentais, a entenderem a importância e os ganhos que terão ao participarem de processos interativos como os proporcionados pelas redes sociais.

Para o contexto deste projeto, a realização do curso foi utilizada a Rede Social Educacional (RSE) Edmodo. Essa que permite o agrupamento de profissionais da mesma área para discussões técnico-científicas, permitindo uma melhor organização de grandes concentrações de dados, já que facilita a troca de informações e materiais ao possibilitar discussões online em tempo real. O Edmodo é uma RSE gratuita que disponibiliza seu serviço online de tal forma a não necessitar de instalações, configurações ou manutenções de hardware para hospedagem do serviço (OLIVEIRA; OLIVEIRA, 2012; ABREU; OLIVEIRA, 2014). O Edmodo atende ainda muito das exigências para ser qualificada como uma RSE, como nas suas plataformas para discussão de determinados tópicos, nos fóruns um assunto pode ser totalmente debatido e pesquisas de opiniões são possíveis no decurso de enquetes. De igual forma, essa RSE fortaleceu os vínculos entre os educadores a partir das interações entre eles, seja através das discussões das questões motivadoras ou através da resolução de dúvidas de seus companheiros no curso promovido pelo presente projeto.

\section{Material e métodos}

A presente investigação teve como objetivo principal traçar o perfil dos docentes participantes do CREA e levantar os requisitos de ferramentas que atendam às reais 
necessidades dos docentes e que promovam uso e adoção dos REA. Para isso, foi realizada pesquisa de base exploratória, buscando traçar um estudo diagnóstico (CERVO; BERVIAN; SILVA, 2007; MARCONI; LAKATOS, 2003), já que se procurou identificar e descrever os conhecimentos prévios dos educadores a respeito das REA's e das ferramentas das TICs.

$\mathrm{Na}$ primeira etapa do projeto foi realizada uma revisão bibliográfica sobre o tema que serviu para conhecer sobre os principais conceitos, definições, autores e materiais relacionados ao CREA, culminando com a seleção e leitura dos materiais mais pertinentes. Passada essa etapa, houve o planejamento do CREA a fim de contemplar os principais assuntos enfatizados pelos autores dos materiais estudados. Além disso, foram selecionados os materiais de referência para o curso e a organização das atividades e avaliações a serem aplicadas no curso. Com isso foi possível elaborar o projeto do curso e o edital para seleção dos alunos do CREA.

Logo em seguida, foi realizada uma busca acerca dos principais sistemas de gerenciamento de aprendizagem online, sendo possível identificar vários Ambientes Virtuais de Aprendizagem (AVA) e Redes Sociais Educacionais (RSE). Contudo, o CREA necessitava de uma plataforma gratuita que não precisasse de instalação local do serviço, a fim de diminuir a necessidade da infraestrutura de Internet local para manutenção e construção do curso online. Além disso, era necessário que tal sistema estivesse disponível 24 horas por dia, 7 dias por semana e durante todo o ano, bem como houvesse ferramentas para criação de avaliações no próprio ambiente para facilitar a criação, correção, apresentação das notas, comentários aos alunos e funções necessárias para interações educacionais em ambientes online, inclusive com possibilidade de aplicativos para dispositivos móveis ou mesmo uso pelos navegadores dos smartphones e tablets (OLIVEIRA; OLIVEIRA， 2012; ABREU; OLIVEIRA, 2014).

Esses fatores, então, contribuíram para a definição do Edmodo como ambiente para oferta do CREA e, consequente, estruturação do curso no referido ambiente. Inclusive houve a postagem de todas atividades do curso logo no primeiro momento, com mensagens $\mathrm{e}$ apresentações/orientações sobre as atividades que ocorreriam de forma agendada para que os participantes focassem apenas nas ações do módulo vigente.

Foram elaborados também materiais para divulgação do CREA nas redes sociais e páginas eletrônicas de parceiros, cuja divulgação e período de inscrições ocorreram por cerca de 30 dias. As inscrições dos alunos do CREA ocorreram por meio de formulário eletrônico, sendo que os documentos comprovatórios e outros necessários para matrícula foram encaminhados por e-mail. O processo de inscrição no CREA ocorreu por meio de formulário online, em que os candidatos declaravam ser professores de escolas públicas ou privadas.

Logo, foram inscritos um total de dezesseis (16) educadores que cumpriam as premissas do edital simplificado lançado e divulgado amplamente pela Internet. $\mathrm{O}$ curso teve uma carga-horária de $40 \mathrm{~h}$, ocorreu na modalidade à distância pelo período de 20 dias e abordou os seguintes assuntos: conceitos, definições, tecnologias e licenças de REAs; modelos de negócios, repositórios e ambientes de compartilhamento de REAs, e PEAs.

O docente, ministrante do CREA, acessava diariamente o Edmodo para acompanhar as discussões, corrigir atividades, responder aos questionamentos dos alunos e postar as notas e demais mensagens de aviso aos alunos.

Deste modo, o curso foi ministrado com exercícios programados, avaliações agendadas, com duração e término preestabelecidos, e com espaços para discussão sobre questões motivadoras sugeridas pelo professor a partir dos materiais didáticos indicados.

O Edmodo permitiu o armazenamento de todos os materiais didáticos do cursos e gerenciamento de todos os alunos, professores e pesquisadores envolvidos. Além disso, a referida RSE tem uma interface intuitiva e bastante parecida com o ambiente da rede social Facebook. As ferramentas existentes no Edmodo já permitiam a criação dos questionários e avaliações em diversas formas, 
contando ainda com espaço para apresentação dos comentários dos professores e organização das notas dos alunos de forma simples e fácil para docentes e discentes.

Cabe destacar que as avaliações foram realizadas através de questões teóricas e realização de discussões nos fóruns, representando atividades de ensino de acordo com as especificidades do curso. Todas as atividades contavam pontuações de 0 (zero) a 10,0 (dez), bem como frequência, conforme o nível de esforço para cada uma dessas atividades. As médias finais foram calculadas a partir da média aritmética de todas as atividades do CREA.

As avaliações escritas contemplaram todos os conteúdos do curso e foram disponibilizados para a leitura. Para aprovação no curso e recebimento do certificado de conclusão do CREA, o aluno deveria:

- Atingir média final igual ou superior a 6,0 (seis), calculado a partir da média aritmética das notas das avaliações realizadas em todo o curso: notas dos fóruns e avaliações de conteúdo.

- Frequentar, no mínimo, 75\% das aulas ministradas e participar das atividades virtuais, cujos valores das frequências por atividade estão definidos na seção seguinte.

Os questionários elaborados para essas avaliações continham questões de múltipla escolha baseadas nos materiais disponibilizados. Cada questionário possuía um valor de 10,0 (dez) pontos, sendo que foi aplicado um questionário por módulo, sendo assim o curso preparou 3 questionários avaliativos. Esses 10,0 (dez) pontos eram somados a outros pontos obtidos de outras atividades e assim era obtida a média aritmética.

O curso possuía como matriz curricular os seguintes assuntos divididos nos módulos (Quadro 1):

\begin{tabular}{|c|c|c|c|c|}
\hline Módulo & Atividades & CH (h) & Notas & Data \\
\hline \multirow{4}{*}{1} & $\begin{array}{l}\text { Fórum 01: Como os REA's poderão contribuir com os processos de Ensino e de } \\
\text { aprendizado no contexto educacional atual? (Edmodo) }\end{array}$ & 8 & \multirow{3}{*}{$\begin{array}{c}\text { De } 0 \\
\text { (zero) } \\
\text { a } 10 \\
(\text { dez) }\end{array}$} & \multirow{4}{*}{$\begin{array}{r}11 \mathrm{a} \\
17 / 05\end{array}$} \\
\hline & $\begin{array}{l}\text { Questionário de satisfação 01 (Marque "Módulo 1" na primeira questão - } \\
\text { http://goo.gl/forms/dpoL53ck7r) }\end{array}$ & 2 & & \\
\hline & Avaliação de conteúdo 01 (Quiz 01 no Edmodo) & 2 & & \\
\hline & Questionário de Sondagem de perfil (http://goo.gl/forms/mTqzXmabZU) & 2 & - & \\
\hline \multirow{4}{*}{2} & $\begin{array}{l}\text { Fórum 02: Como seria um modelo de negócios adequado para a difusão, uso, e } \\
\text { compartilhamento dos Recursos Educacionais Abertos (REA's)? (Edmodo) }\end{array}$ & 8 & \multirow{3}{*}{$\begin{array}{c}\text { De } 0 \\
\text { (zero) } \\
\text { a } 10 \\
(\mathrm{dez})\end{array}$} & \multirow{4}{*}{$\begin{array}{r}18 \text { a } \\
24 / 05\end{array}$} \\
\hline & $\begin{array}{l}\begin{array}{l}\text { Questionário de satisfação 02 (Marque "Módulo 2" na primeira questão - } \\
\text { http://goo.gl/forms/dpoL53ck7r) }\end{array} \\
\end{array}$ & 2 & & \\
\hline & Avaliação de conteúdo 02 (Quiz 02 no Edmodo) & 2 & & \\
\hline & \begin{tabular}{|l}
$\begin{array}{l}\text { Questionário de Levantamento de requisitos de repositório de } \\
\text { (http://goo.gl/forms/oFolnLhk64) }\end{array}$ \\
\end{tabular} & 2 & - & \\
\hline \multirow{4}{*}{3} & $\begin{array}{l}\text { Fórum 03: Como as práticas educacionais abertas podem influenciar na melhoria } \\
\text { significativa da educação? (Edmodo) }\end{array}$ & 8 & \multirow{3}{*}{$\begin{array}{c}\text { De } 0 \\
\text { (zero) } \\
\text { a } 10 \\
(\text { dez) }\end{array}$} & \multirow{3}{*}{$\begin{array}{r}25 \mathrm{a} \\
01 / 06\end{array}$} \\
\hline & Avaliação de conteúdo 03 (Quiz 03 no Edmodo) & 2 & & \\
\hline & $\begin{array}{l}\text { Questionário de satisfação 03 (Marque "Módulo 3" na primeira questão - } \\
\text { http://goo.gl/forms/dpoL53ck7r) }\end{array}$ & 2 & & \\
\hline & Total & 40 & & \\
\hline
\end{tabular}

Quadro 1: Módulos com atividades do CREA.

Fonte: Pesquisa direta.

$\mathrm{O}$ processo de sondagem inicial teve o intuito de conhecer as dificuldades e o nível de conhecimento dos educadores matriculados no CREA a fim de que as ações de execução do curso fossem realizadas tendo em vista o público-alvo do curso. Para isso, foi utilizado o questionário online de sondagem inicial (https://goo.gl/pDw6kf), com o qual 
identificaram-se os pontos que os participantes do CREA não dominavam bem ou com quais ferramentas ou plataforma não tinham tido contato ainda. Destinou-se também espaços para uma autoavaliação. É importante enfatizar que os participantes do CREA tomaram conhecimento sobre a pesquisa envolvida no curso e optaram por participarem ou não da investigação mediante o Termo de Consentimento Livre e Esclarecido.

Os alunos também realizavam avaliações de satisfação ao final de cada módulo para que se pudesse identificar os níveis de contentamento em relação aos conteúdos, professores, ambiente de interação, equipe de coordenação, além de autoavaliação do aluno (http://goo.gl/forms/dpoL53ck7r).

As atividades dos três módulos e as questões motivadoras das discussões nos fóruns versaram basicamente sobre os materiais sugeridos para leitura em cada seção. As respostas aos questionamentos das discussões dos módulos foram organizadas de forma hierárquica, de modo a facilitar o acompanhamento de toda a discussão pelos participantes dentro do prazo estabelecido para o módulo. Percebeu-se também que o professor do curso buscou motivar a participação e o acompanhamento dos alunos neste momento de interação com respostas e comentários rápidos aos questionamentos e contribuições apresentadas por cada um dos participantes.

O CREA foi destinado para professores e demais interessado em REA's, sendo possível atender aos docentes do Brasil, porém houve participantes somente dos Estados de Pernambuco e Ceará, que atuam nos seguintes municípios: Juazeiro do Norte (CE), Petrolina (PE), Salgueiro (PE), Fortaleza (CE), Maracanaú (CE) e Caucaia (CE). Houve participantes das mais diversas áreas do conhecimento e com diversos níveis de conhecimento sobre o assunto, sendo possível perceber a participação de pesquisadores interessados na área com mestrado ou em realização de doutorado e que realizaram suas pesquisas na área.

\section{Resultados e discussão}

Dentre os participantes matriculados no CREA, $81,25 \%$ dos inscritos pertencem às redes de ensino público, enquanto $18,75 \%$ são da rede privada. Percebeu-se também que, em média, os participantes possuem mais de 30 anos e que todos já utilizaram Recursos Digitais Educacionais (RED). Porém alguns participantes afirmaram ter dificuldades para inserir esses recursos em seus contextos educacionais, tiveram dificuldades em adequar os métodos a sua realidade ou, ainda, não tiveram oportunidade.

Nesse processo de sondagem inicial foi encaminhado o questionário com o intuito de fazer o levantamento que se trata dos seus conhecimentos prévios sobre REA e RED. Já que diante dessas informações seria possível definir melhores estratégias para o curso. Assim, os referidos formulários foram respondidos pelo link: http://goo.gl/forms/mTqzXmabZU.

A análise do questionário de sondagem permitiu saber que $80 \%$ dos participantes utilizaram o Google e os mensageiros online com viés educacional; enquanto o YouTube, tradutores online, editores de slides e redes sociais foram utilizados por todos; mas ninguém utilizou o Scratch. Isso denota o quanto essa última ferramenta é desconhecida entre os participantes e que não há aplicação em suas práticas pedagógicas dela. Além disso, aquelas ferramentas elencadas com percentuais de utilização inferiores a $80 \%$ têm potenciais para maiores aplicações com conceitos de REAs, mas precisarão ter práticas pedagógicas desenvolvidas e divulgadas entre os docentes. Já em relação à frequência de uso de computadores portáteis e acesso à internet, $100 \%$ dos participantes relataram utilizar diariamente (Gráfico 1).

O conhecimento acerca da definição de REA era de domínio de $80 \%$ dos alunos, mas todos já tinham lido algum material sobre o tema nas mais diversas situações (mestrado, outros cursos, objetos midiáticos, portais educacionais, indicação de amigos e leitura de artigo, revista ou outro material impresso); enquanto $40 \%$ já participaram de algum experimento com REA. Além disso, 40\% mencionaram que tinham forte interesse no 
(OLIVEIRA; ABREU, GOMES, 2015)

estudo sobre o tema, enquanto os demais possuíam interesse muito forte.

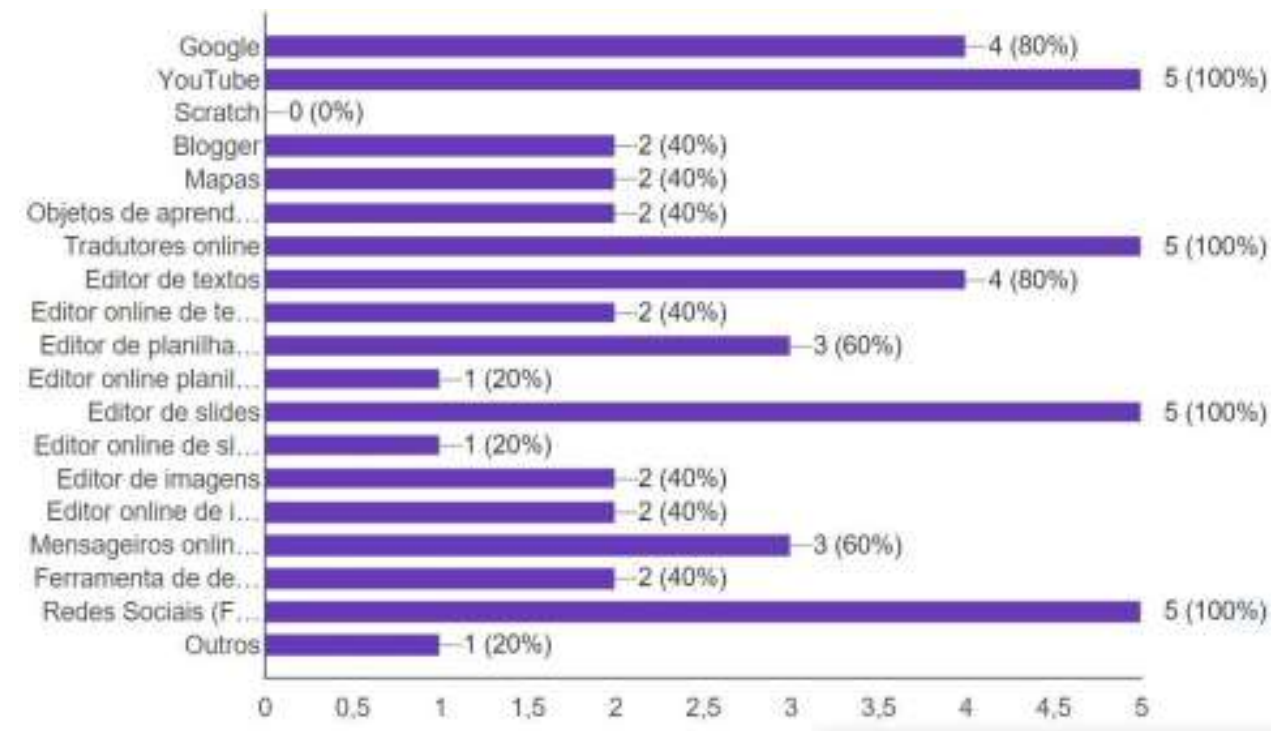

Gráfico 1: Uso de TICs com finalidade educacional pelos participantes do CREA. Fonte: Pesquisa direta.

Quando questionados se eles indicariam o uso de REA's aos seus amigos, se eles conseguiram aprender por meio dos REA's, se utilizariam REA's a partir de agora e se acreditavam que os REA's poderiam ajudar no seu aprendizado, $40 \%$ relataram que muito provavelmente cumpririam todos esses tópicos, $40 \%$ descreveram que as chances eram fortes para o cumprimento desses tópicos e os outros $20 \%$ não responderam.

Sobre REA's e seus repositórios utilizados, todos os participantes afirmaram ser importante o uso dos REA's pelo navegador web e a possibilidade de download do REA direto pelo browser, porém $40 \%$ afirmaram ser importante as alterações dos REAs mesmo pelo navegador, o mesmo percentual foi de participantes que afirmaram não ser importante que as alterações ocorram a partir do navegador e os demais relataram desconhecer tal possibilidade. Já $60 \%$ dos participantes afirmaram ser importante a possibilidade de download do recurso a partir do repositório e posterior alteração em máquina local.

Portanto, as análises do questionário de sondagem serviram para tornar a condução do curso pelo professor mais próxima da realidade dos alunos matriculados no CREA, pois foi possível identificar o nível de conhecimento sobre os conceitos, ferramentas e práticas baseadas em REAs.

Já no módulo 2, os participantes realizaram uma atividade de levantamento de requisitos de um repositório de REA voltado ao atendimento das reais necessidades dos docentes e demais interessados no uso, difusão, compartilhamento e desenvolvimento de REAs: http://goo.gl/forms/oFolnLhk64.

Os participantes do CREA consideraram como importante ou muito importante que um repositório de REA contemplem as seguintes funções: manter padrões de organização de layout, ser fácil de utilizar, manter suas informações previamente salvas para acessos futuros, estar disponível para todo e qualquer momento, ser acessível a partir de qualquer plataforma, manter orientações aos usuários acerca da legislação pertinente ao uso e compartilhamento de REAs e manter opções de ajuda ou de explicações para cada função.

Os partícipes ainda relataram a importância da existência de ferramenta de autoria de REAs no próprio repositório, de tal forma que atendam aos seguintes aspectos: possibilitar a utilização online dos recursos, permitir o download dos recursos implementados, ser acessível por qualquer dispositivo, estar disponível para qualquer 
sistema operacional (SO), editar recursos variados, permitir o upload de recursos para edição, armazenar os projetos online, incorporar recursos salvos em outros ambientes, disponibilizar classes de códigos prontos, permitir a reutilização de códigos completos próprios, permitir a reutilização de códigos completos compartilhados por outros usuários, permitir a reutilização de partes de códigos, permitir a reutilização de partes de códigos compartilhados por outros usuários, permitir a criação de classes, permitir a edição de classes criadas por outros usuários, não utilizar profundos conhecimentos de informática ou linguagem de programação, ser fácil de utilizar, permitir a criação em diversos formatos, permitir a edição em diversos formatos, ter templates de exemplo para edição, ter versão online, integrar-se com repositório de recursos, ter versão para desktop (versão offline e instalável) e ter versão para dispositivos móveis (versão off-line e instalável).

Já em relação aos fóruns de discussões, o professor iniciava na segunda-feira a atividade semanal com uma pergunta motivadora sobre o tema vigente e os participantes deveriam apresentar seus posicionamentos acerca do assunto baseado nos materiais de leitura sugeridos. Contudo, percebeu-se que as postagens ocorriam apenas mais próximas do final de semana ou mesmo no último dia do prazo, no caso, o domingo. Os participantes apresentavam suas considerações, mas não acompanhavam a discussão, já que o professor lia todas as postagens e sempre apresentava mais alguma indagação para complementar a discussão, bem como para motivar a continuidade do diálogo.

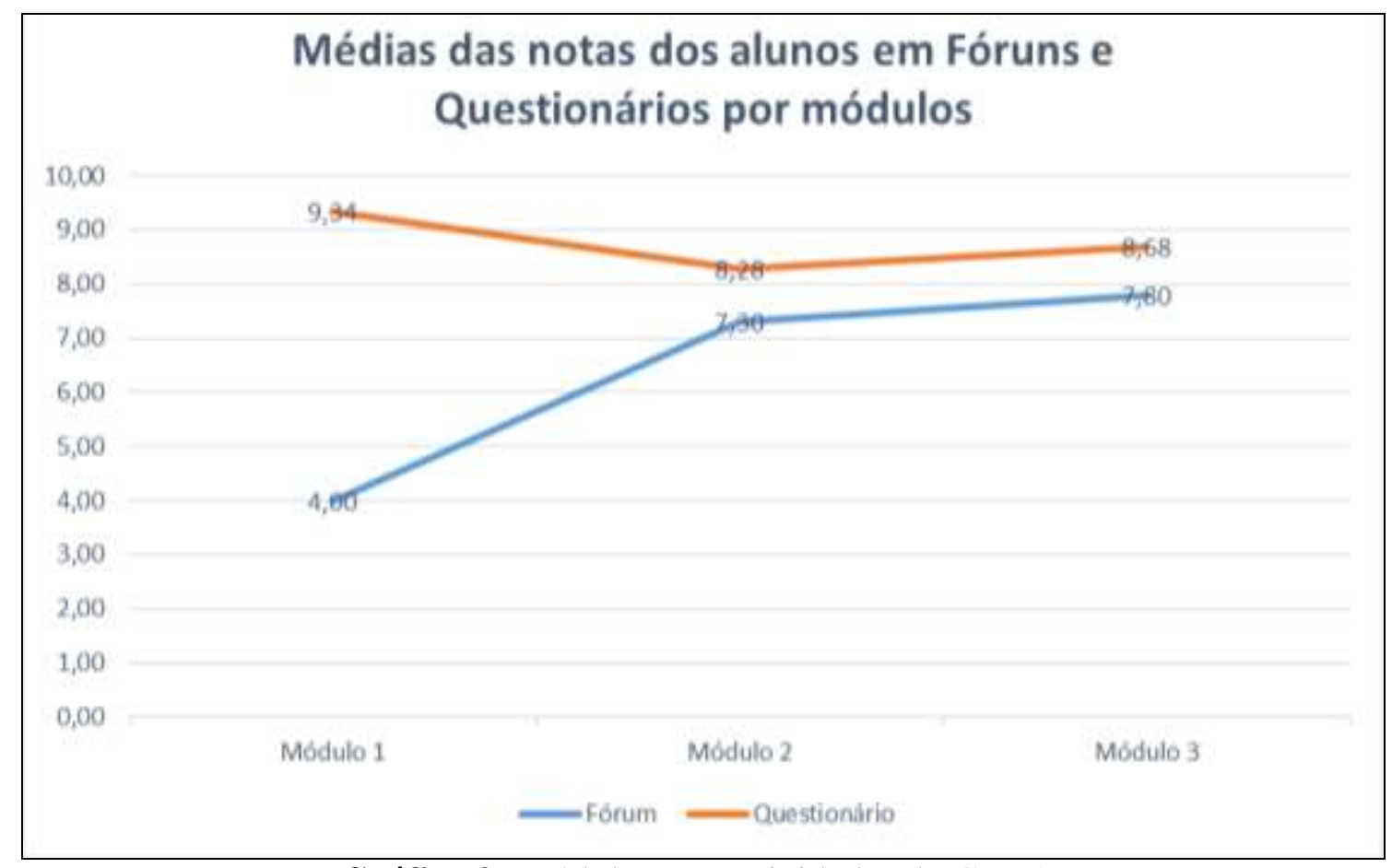

Gráfico 2: Módulos com atividades do CREA.

Fonte: Pesquisa direta.

No entanto, no decorrer do curso, foi possível perceber uma maior atenção dos alunos em relação aos informes repassados e, consequentemente, maior participação de todos e acompanhamento das discussões durante a semana. Compreenderam que postagens deveriam ocorrer preferencialmente no início da semana, pois todos poderiam colaborar com trocas de informações, bem como o professor poderia apresentar um feedback mais adequado. Assim, foi possível perceber na última semana que alunos atuaram de forma intensa e tiveram melhores rendimentos, se comparado entre os módulos 1 ao 3, principalmente, as médias das notas obtidas pelos participantes nas discussões nos fóruns 
no decorrer dos módulos, enquanto houve um pequeno decréscimo nas médias das notas das avaliações de conteúdos, que podem ser geradas pelos materiais com mais páginas para leitura e com conteúdos que aprofundaram um pouco mais nos aspectos teóricos (Gráfico 2).

Dentre os participantes matriculados no CREA, apenas cinco alunos $(31,25 \%)$ foram aprovados, ou seja, concluíram o curso com média final igual ou superior a 6,0 (seis) e receberam o certificado de participação.

As respostas dos questionários de satisfação explicitaram a desconstrução do preconceito existente por muitas pessoas de que cursos semipresenciais ou à distância são de má qualidade, pois os materiais disponibilizados foram considerados de boa qualidade e os participantes do curso demonstraram que tinham flexibilidade para estudarem e participarem dos fóruns em horários mais convenientes. Porém, cumpriram rigorosamente os prazos estabelecidos para conclusões das atividades em cada um dos módulos. Além disso, o professor do curso esteve sempre atuante pelo Edmodo de modo a interagir com cada aluno, responder seus questionamentos e passar informações do curso em menos de um $24 \mathrm{~h}$.

\section{Conclusões}

O CREA conseguiu realizar os objetivos previstos e ofereceu contribuições para a comunidade de profissionais da educação e demais interessados com a realização da formação de educadores em REA's, cujos participantes poderão se tornar multiplicadores dos conceitos estudados, bem como divulgadores de exemplos de recursos e PEAs, sendo ainda possível que tais participantes se tornem desenvolvedores de conteúdo.

Além disso, pode-se também mencionar que os partícipes também estarão aptos a desenvolverem suas PEAs ou adequarem exemplos exitosos aos seus contextos educacionais. Há também ferramentas das TICs com potencial ainda para serem exploradas, conforme o levantamento realizado na pesquisa. Isso implica mais pesquisa e estudos de casos baseados em TICs a fim de gerar novas PEAs e compartilhar tais casos de sucessos nos repositórios de REAs ou em espaços reservados para tal assunto.

O curso teve apenas 5 alunos aprovados, dentre os 16 (dezesseis) matriculados. Pode-se considerar que os demais matriculados desistiram, pois enviaram suas documentações, mas não realizaram o cadastro no ambiente online. O alto índice de desistência $(68,75 \%)$ pode ter como uma das causas no curto período do curso disponível para apresentar a ferramenta Edmodo no momento inicial do CREA, já que não houve um módulo para ambientação dos alunos. Além disso, pode-se supor também que a desistência de alguns alunos ocorreu por causa do uso da plataforma online para oferecimento do curso ou mesmo pela oferta do curso na modalidade à distância.

Contudo, o uso do ambiente online também proporcionou a participação de pessoas de diferentes Estados, algo impossível ou que geraria dificuldades de deslocamentos dos participantes para o curso presencial que seria oferecido no sertão pernambucano, principalmente, daqueles participantes que declararam residir em cidades a cerca de 600 $\mathrm{km}$ de distância do município polo do CREA.

\section{Referências}

ABREU, K. F; OLIVEIRA, F. K. Redes sociais educacionais: instrumentos auxiliares no ensino de língua espanhola. In: LIMA, S. C.; BATISTA JUNIOR, J. R. L. (Org.) Linguagens: relatos de experiências da educação profissional e tecnológica. Natal: IFRN, 2014. p. 95-98.

AMIEL, T.; OREY, M.; WEST, R. E. Recursos educacionais abertos (REA): modelos para localização e adaptação. ETD: Educação Temática Digital, n. 12, p. 112-125, 2011.

BRASIL. Constituição (1988). Constituição da República Federativa do Brasil: promulgada em 5 de outubro de 1988. Contém as emendas constitucionais posteriores. Brasília, DF: Senado, 1988. 
CERVO, A. L.; BERVIAN, P. A.; SILVA, R. Metodologia científica. $6^{\mathrm{a} e d .}$ São Paulo: Pearson Prentice Hall, 2007.

CONOLE, G.; EHLERS, U. et al. Relatório 3.1 do projeto OPAL 2010. Disponível em: http://www.oer-quality.org/publications/projectdeliverables. Acesso em: 12 de outubro de 2012.

CORNILS, P. Um computador por aluno. Quando? Onde? Como?. In: A Rede, v. 7, n. 74, p. 10-17, 2011. Disponível em: http://www.arede.inf.br/inclusao/edicoesanteriores/184-edicao-no-74outubro2011/4795-capa. Acesso em: 12 de outubro de 2012.

CUBAN, L. Oversold and underused: computers in the classroom. Cambridge, Massachusetts: Harvard University Press, 2001.

CYSNEIROS, P. G. Programa nacional de informática na educação: Novas tecnologias, velhas estruturas. In: BARRETO, R. G. (Ed.). Tecnologias educacionais e educação a distância: aliando políticas e práticas. Rio de Janeiro: Quartet, 2001.

\section{DECLARAÇÃO DA CIDADE DO CABO. Declaração de Cidade do Cabo para Educação Aberta: Abrindo a promessa de Recursos Educativos Abertos. Cape Town, $2007 . \quad$ Disponível em: http://www.capetowndeclaration.org/translation s/portuguese-translation. Acesso em: $12 \mathrm{de}$ outubro de 2012.}

FSF (FREE SOFTWARE FOUNDATION). Libre Documentation Explained. Disponível em:

https://www.gnu.org/gwm/libredocxml/x53.htm 1. Acesso em: 11 de novembro de 2014.

LAVINAS, L.; CAVENAGHI, S. Avaliação de Impacto Social do Projeto UCA-TOTAL. 2010.
MARCONI, M. A.; LAKATOS, E. M. Fundamentos de metodologia científica. 5. ed. São Paulo: Atlas, 2003.

MONTOYA, M. S. R.; AGUILAR, J. V. B. Recursos educativos abiertos en ambientes enriquecidos con tecnología. México: Editorial INNOVATE, 2010.

MORAIS, E.; RIBEIRO, A.; AMIEL, T. Recursos educacionais abertos (REA): um caderno para professores. Campinas, SP: Educação Aberta, 2011. Disponível em: http://goo.gl/J6S8xM. Acesso em: 21 de julho de 2014.

OLIVEIRA, F. K.; OLIVEIRA, O. S. Edmodo: uma rede social educacional. In: Anais do $4^{\circ}$ Simpósio Hipertexto e Tecnologia na Educação. Recife: EDUFPE/Pipa Comunicação, 2012, p. 1-16. Disponível em: Acesso em: 21 de julho de 2014.

OLIVEIRA, F. K. O vídeo pela Internet como ferramenta educacional no ensino da Geometria. 2010. 102f. Dissertação (Programa de Pós-Graduação em Ciências da Computação) - UECE, Fortaleza, 2010.

PADOVAN, V. T.; SANCHES, L. M. P.; CARITÁ, E. C. Uso de redes sociais n o processo ensino aprendizagem: Avaliação de suas características. In $\mathbf{1 7}^{\mathbf{0}}$ Congresso Internacional de Educação a Distância, XVII, 2011, Manaus-AM. Anais do $17^{\circ}$ Congresso Internacional de Educação a Distância. Ribeirão Preto-SP: Associação Brasileira de Educação a Distância, 2011, p.1$10 . \quad$ Disponível em: http://www.abed.org.br/congresso2011/cd/61.p df. Acesso em: 12 de outubro de 2012.

SILVA, A. P. S. S.; COGO, A. L. P. Aprendizagem de punção venosa com objeto educacional digital no curso de graduação em enfermagem. Revista Gaúcha de Enfermagem. Porto Alegre/RS, v. 28, n. 2, p.185-192, 2007. 
(OLIVEIRA; ABREU, GOMES, 2015)

SORJ, B.; LISSOVSKY, M. Internet nas escolas públicas: política além da política. Centro Edelstein de Pesquisas Sociais. Rio de Janeiro. 2011.

TAURION, C. Software Livre Potencialidades e Modelos de Negócios. $1^{\text {a }}$ ed. São Paulo: Brasport, 2004.

UNESCO (ORGANIZAÇÃO DAS NAÇÕES UNIDAS PARA EDUCAÇÃO, CIÊNCIA E CULTURA). UNESCO and education: "Everyone has the right to education". UNESCO. Paris. 2011

WILEY, D. A. The Current State of Open Educational Resources. 2005. Disponível em: http://goo.gl/HAR4s5. Acesso em: $12 \mathrm{de}$ outubro de 2012. 